\title{
Research on the project management of BIM project from the perspective of enterprise strategy
}

\author{
Wang Yongling ${ }^{1}$, Liu Jun ${ }^{2}$ \\ 1. Avic Apc Changsha Design\&Research Co., Ltd , Changhsa, China \\ 2. China Aviation Planning And Design Institute Co.Ltd Of Aircraft Engineering Design And \\ Research Institute, City , China \\ Email: yonglwngcs@sina.com
}

Key words: BIM; information model; modeling; virtual construction; simulation

\begin{abstract}
With the introduction of BIM Technology, the traditional construction project management model innovation will can to realize data sharing in a common platform to participate in many of the units, and the construction project management more convenient and effective. The due to long engaged in technology research and development and application of Bim and construction management, the future will be in construction project management of Bim and we were technology sharing and exchange, such as the construction schedule, cost, quality and safety control, application of Bim and construction simulation and construction green BIM application, and people, machine, material, method, central management of BIM applications.
\end{abstract}

\section{Introduction}

BIM(Building Information Modeling), Building information model in our country. The idea of BIM was first proposed in 1975. With the change of time, the rapid increase of the performance of computer hardware and software development of the BIM concept is change rapidly, the construction personnel more and more accepted by the. BIM technology is a kind of optimization design means of management is active in the construction project whole life cycle. Through the buildings or structures and the construction site of the 3D model and the construction progress of the link, and construction resources, safety and quality and site layout information are integrated, the realization of the simulation based on BIM and network construction schedule, manpower, materials, equipment, cost, safety, quality and site cloth 5D dynamic integrated management and construction process of the $5 \mathrm{D}$ visual. The engineering of basic information management system with BIM as the core in the construction industry are widely used, will become a powerful force in the domestic application of BIM.

\section{Based on the application of BIM technology in construction}

Based on BIM virtual construction, the construction itself does not consume resources construction, but can according to visual effects to see and understand the process and result of construction, can greatly reduce rework cost and management cost, reduce the risk and strengthen the management of the construction process control. Process modeling is the process of virtual construction is try to build process, the smooth implementation of the construction process is in under the guidance of the effective construction scheme and construction plan preparation is mainly according to the experience of project manager and chief engineer of the project and the project department, the feasibility of construction scheme has been the industry's attention because of the single building products and repeatability, the construction scheme is not repeatable. General situation, when a project is about to end, a complete set of construction plans to show in front of. Construction schedule delay, safety, quality problems, rework rate, cost of construction has become a common problem of existing construction projects. Before the construction, it is very necessary to make a perfect construction plan, and it is also very important. Virtual construction technology can not only detect and compare the construction plan, but also can optimize the construction program. 
First according to the construction drawings, the entire construction project is divided into various components, and through the 3D component model, their size, volume and weight are measured directly down, and the types of materials used, types of record. Secondly, according to the main components of the selection of construction equipment, equipment, determine the construction method. By building the component modeling, it can help the construction party to study how to carry out the construction and installation of the components in the field. Before construction, construction scheme makers first detailed construction site survey, focus on solving the construction site overall planning, site approach position, loading and unloading zone position, heavy machinery and positions of the dangerous region, and ensure the building components in heavy machinery safety effective working range; using five dimensional modeling, model construction process, the lifting component path, the dangerous region, vehicle import and site conditions, loading unloading etc.. Construction site virtual dimension Quanzhen model can be intuitive, convenient to assist managers to analysis of site constraints, find out potential problems, formulate feasible construction method. It is conducive to improve the efficiency and reduce the possibility of the existence of loopholes in the traditional method of construction site layout, as soon as possible to find the problems of the construction plan design and construction scheme, improve the productivity and safety of the construction site.

Construction methods are usually determined by the use of engineering products and construction machinery, the overall planning of the site, site space, mechanical production capacity, mechanical safety and disassembly methods and determine the selection of construction machinery. Temporary facilities for construction services, its layout will affect the construction safety, quality and production efficiency, a fifth dimensional model of Quanzhen virtual temporary facilities, the construction unit of the useful can realization of layout and use of temporary facilities, can also help the construction unit prior to accurately estimate the required resources, and assessing the safety of temporary facilities, whether for construction, as well as possible design errors found.

5D Quanzhen platform model of virtual prototype engineering construction, the construction process of visualization simulation, including engineering design, field environment and resource usage, with greater predictability, will change the mode of traditional construction plan, organization. The construction method of visualization is all project participants before construction can clearly know all construction contents and their responsibilities to promote effective communication in the process of construction, it is current assessment of the construction method, found the problem, simple and economical, safe method for construction risk evaluation. The use of BIM virtual construction, need to determine in advance the following information: a five dimensional model design and site construction of environment; according to the component selection of construction machinery and mechanical operation mode; determine the manner and order construction; determine the required temporary facilities and installation position. BIM Technology to Quanzhen simulation operation of the whole process of construction, project management, engineering and technical personnel and construction personnel can understand every step of the construction activities. If problems are found, the engineering and technical personnel and construction personnel can put forward the new method, and the new method is simulated to verify its feasibility and the construction process of trial and error, it can do in the prior to construction of the vast majority of construction risks and problems can be identified, and solved efficiently.

Virtual construction make construction more visual, which greatly facilitated the communication among project participants, especially do not have the engineering professional knowledge of staff, through the construction simulation can increase the project involved in the understanding of the parties to the contents of the project and completion of the works guarantee measures. Visualization of the construction process, so that BIM become a convenient for the construction of the parties involved in the exchange of communication platform. Through the visual simulation of the scene to shorten the site staff familiar with the project construction content, the method of time, reduce the site staff in the early construction of the time and cost of making mistakes. Can also speed up and deepen the speed and depth of the project involved in personnel training, quality, safety, progress, 
cost management and control of everyone involved.

BIM Can also provide visual construction space. BIM visualization is dynamic, the construction space with the progress of the project will continue to change, it will affect the working efficiency of workers and construction safety. Through the visual simulation of the staff's construction situation, you can see the image of the construction work surface, the construction of the location of the situation, and to assess the progress of the construction of these working space availability, security. BIM provides the construction budget accuracy, BIM model is known as parametric model, so modeling at the same time, all kinds of construction is endowed with the constraint parameters of sizes, types, materials, and so on, BIM is through the visual design environment repeatedly testing and modifying the results, by the export of materials and equipment data have very high credibility and application of BIM model derived data can be applied directly to the project budget and cost control, construction and final accounts provide a favorable basis. In the past, the construction of the final accounts are holding the drawings in the calculation, with the model, the data is fully automatic generation, the accuracy of the final accounts, the budget increased.

Construction organization is the implementation of an important means of scientific management of construction activities, which determines the various stages of construction preparation work and coordinate the relationship between the construction unit, the type of construction and the resources of the construction process. BIM can carry on the visibility simulation to the key and difficult part of construction, and analyze and optimize the construction scheme according to the network time standard. In order to improve the implementation of the plan, the key part of the construction or the construction of the key parts of the construction process, construction site layout and other construction guidance measures are simulated and analyzed. According to the construction organization design for computer preview using BIM technology to improve the construction of the complex building system. With Bim in the construction simulation, project managers can intuitively understand the interval construction process of time nodes and key procedure, and clearly grasp the difficulties and points in the construction process, can also further the construction scheme optimize, to improve application efficiency and construction scheme of safety. Visualization of model output construction pictures and distributed to the construction personnel can be as a visualization of the operating instructions or technical disclosure to the scene to guide the construction and convenient on-site construction management personnel take the drawings to guide the construction and management of the site.

\section{Summary}

BIM (building information modeling is introduced, will promote the standardization of engineering construction, prefabricated, from some kind of meaning is for engineering industry the introduction of a production line, it to reduce the one-time risks and costs increased.

Based on BIM Technology of virtual construction, the construction units can achieve the following objectives: create, analysis and optimization of construction schedule; the feasibility of the construction method for the analysis of specific projects to use; the visual simulation of the construction process, early detection of construction problems, to eliminate the risk of construction; image communication tool, the project participants to better understand the scope of the project, provide image operation instructions or technical clarification; can more effectively manage design changes; new trial and error, error correction, concepts and methods. At present, not only for construction project, but also extended to the bridge, tunnel, wind electricity, highways, and equipment installation engineering field, such as the Shanghai international financial center, Kunming new airport equipment installation, Xing Fen expressway project. BIM it can improve the construction general contracting enterprise integrated capability, can reasonably control the project cost and improve construction effect, realize the green construction concept, is the effective way of the informatization construction of construction enterprises. 


\section{Reference}

[1] Jiang D, Xu Z, Lv Z. A multicast delivery approach with minimum energy consumption for wireless multi-hop networks[J]. Telecommunication Systems, 2015: 1-12.

[2] Liu Y, Yang J, Meng Q, et al. Stereoscopic image quality assessment method based on binocular combination saliency model[J]. Signal Processing, 2016, 125: 237-248.

[3] Lv Z, Tek A, Da Silva F, et al. Game on, science-how video game technology may help biologists tackle visualization challenges[J]. PloS one, 2013, 8(3): e57990.

[4] Xiaolei Zhang, Yong Han, Dongsheng Hao and Zhihan Lv. ARPPS: Augmented Reality Pipeline Prospect System. 22th International Conference on Neural Information Processing (ICONIP 2015), Istanbul, Turkey. In press. 